\title{
Relationship Between Morphological Characteristics and Dynamic Running Parameters in the Case of Boys Aged 10-12 years
}

\author{
Slavenko Likic, Izet Bajramovic and Damira Vranesic-Hadzimehmedovic \\ University of Sarajevo, Faculty for Sport and Physical Education, Sarajevo, Bosnia and Herzegovina
}

\begin{abstract}
A B S T R A C T
The aim of the research is to determine the relationship between morphological characteristics and dynamic parameters of running in the case of boys aged 10-12 years. The study was conducted on a sample of 75 respondents, who are separated from the fourth-grade elementary school population. Morphological characteristics are measured by a set of fifteen variables: longitudinal dimensionality (3 variables), transversal dimensionality (4 variables), volume and body mass (4 variables), fatt tissue (4 variables), and body mass index. Dynamic parameters of running were estimated by measuring the passing time at $5 \mathrm{~m}$ segments of the whole distance. Variables of dynamic running parameters have achieved statistically significant correlation with variables of transversal dimensionality, volume and body mass and fat tissue $(p<0.05)$. Also, statistically significant correlation $(p<0.01)$ of mean intensity was obtained between body mass index and all variables of dynamic running parameters. Based on the results of dynamic running parameters it can be concluded that the analyzed sample of boys aged 10-12 years is characterized by the following pattern of running structure at 50 meters: the acceleration phase lasts from the start to the fifteen meters section; stable running phase lasts from 15 to 40 meters, indicating that the maintenance length of the maximum speed level is 25 meters; and the deceleration phase of running lasts from 40 to 50 meters.
\end{abstract}

Key words: Bio-Motor Potential, Model of Running Structure, Boys Aged 10-12 Years

\section{Uvod}

Trčanje predstavlja prirodni ciklični oblik lokomocije čovjeka. Trčanje u formi sprintanja je samo jedan u mnoštvu mogućih oblika izražavanja izuzetno kompleksne motoričke sposobnosti koja se općenito odnosi na brzinu. Svaku sprintersku dionicu čini struktura od četiri zasebne, ali integrirajuće etape (Smajlović, 2010): start (faza latentnog vremena reakcije na startni signal i manifestne startne akcije); startna progresija (faza akceleracije brzine, traje do momenta dostizanja maksimalne brzine na sprinterskoj dionici); trčanje na distanci (faza održavanja dostignutog nivoa maksimalne brzine); finiširanje $i$ ulazak u cilj (faza deceleracije brzine).

Maksimalna brzina trčanja je zapravo rezultat optimalnog odnosa dva osnovna kinematička parametara koji se odnose na dužinu i frekvenciju koraka. Ovi kinematički parametri su u međuzavisanom odnosu, a ulovljeni su procesima centralne regulacije kretanja, morfološkim karakteristikama, motoričkim sposobnostima i energetskim procesima. Najpovoljniji odnos vrijednosti ova dva kinematiča parametra trčanja pri atletskom sprintu je determiniran antropometrijskim karakteristikama i motoričkim sposobnostima (Mero, Komi i Gregor, 1992). Dužina koraka uglavnom zavisi od visine tijela i dužine nogu. S druge strane, frekvencija koraka zavisi od funkcioniranja centralnog nervnog sistema, te je također izrazito genetski određena (Čoh, Mihajlovič i Praprotnik, 2001). Rezultatski potencijal u atletskom sprintu je u najvećoj mjeri određen sa dva faktora: nivoom maksimalne brzine trčanja i sposobnošću akceleracije brzine (Smajlović, 2010).

Trčanje je elementarna urođena forma kretanja sa već izgra- đenim programom u centralnom nervnom sistemu. Efikasnost trčanja sa aspekta brzine je relativna individualna kategorija, te zavisi od različitih naslijeđenih funkcija. U razvoju djece se često koristi termin „Prirodni biološki razvitak sprinterske brzine“, koji zavisi od visine tijela, tjelesne mase, razvoja bio-motoričkih sposobnosti i forme motoričkog stereotipa kretanja (Bračič, Tomažin, Čoh, 2009).

Maksimalna brzina trčanja se razlikuje i povećava uporedo sa starijim uzrasnim skupinama (Praprotnik i Čoh, 2001). Tokom adolescencije, različite morfološke karakteristike imaju značajan utjecaj na karakteristike trkačkog koraka, prije svega zbog dužine poluga koje imaju značajan utjecaj na tehniku trčanja. Tri važna perioda rasta i razvoja djece: a.) prva i druga uzrasna skupina od 7-8 i 9-10 godina koje karakterizira usporen tjelesni rast $\mathrm{i}$ intenzivan rast mišića, b.) treća uzrasna skupina od 11-12 godina sa najbržim tjelesnim rastom i povećanjem tjelesne mase, i c.) četvrta uzrasna skupina od 13-14 godina u kojoj se procesi tjelesnog rasta i razvoja umiruju i stabiliziraju (Malina 1984, Buenen \& Malina, 1988).

Istraživanjem se pokušala utvrditi povezanost između morfoloških obilježja i dinamičkih parametara trčanja, u svrhu sagledavanja bio-motoričkog potencijal brzine trčanja dječaka uzrasta 10-12 godina.

\section{Metod}

Istraživanje je provedeno na uzorku od 75 ispitanika, dječaka uzrasta 10-12 godina, a koji su izdvojeni iz populacije učenika četvrtog razreda osnovne škole (Sarajevo, Bosna i Hercegovina). 
Morfološka obilježja su izmjerena setom od petnaest varijabli: longitudinalna dimenzionalnost skeleta (3 varijable), transverzalna dimenzionalnost skeleta (4 varijable), volumen i masa tijela (4 varijable), potkožno masno tkivo (4 varijable), te izvedena varijabla indeksa tjelesne mase (body mass index). Dinamički parametri trčanja su procijenjeni mjerenjem vremena postignutog na pojedinim segmentima dionice trčanja na 50 meta- ra. Za potrebe ovog istraživanja je korišten elektronski mjerni sistem i posebno dizajnirani računalni program "BRZ", koji omogućava pohranjivanje podataka o postignutim prolaznim vremenima od starta do cilja tretirane dionice trčanja. Dinamički parametri trčanja su obuhvatili set od 18 varijabli: prolazno vrijeme (9 varijabli) i brzina pri svakom prolaznom vremenu ( 9 varijabli) pri trčanju na 50 metara (tabela 1$)$.

Tabela 1. Varijable dinamičkih parametara trčanja na $50 \mathrm{~m}$

\begin{tabular}{clc}
\hline Varijabla & \multicolumn{1}{c}{ Naziv varijable } & Mjerna jedinica \\
\hline DT5m & Prolazno vrijeme trčanja na $5 \mathrm{~m}$ & $\mathrm{~s}$ \\
DV5m & Brzina trčanja na $5 \mathrm{~m}$ & $\mathrm{~m} / \mathrm{s}$ \\
DT10m & Prolazno vrijeme trčanja na $10 \mathrm{~m}$ & $\mathrm{~s}$ \\
DV $10 \mathrm{~m}$ & Brzina trčanja na $10 \mathrm{~m}$ & $\mathrm{~m} / \mathrm{s}$ \\
DT15m & Prolazno vrijeme trčanja na $15 \mathrm{~m}$ & $\mathrm{~s}$ \\
DV $15 \mathrm{~m}$ & Brzina trčanja na $15 \mathrm{~m}$ & $\mathrm{~m} / \mathrm{s}$ \\
DT20m & Prolazno vrijeme trčanja na $20 \mathrm{~m}$ & $\mathrm{~s}$ \\
DV20m & Brzina trčanja na $20 \mathrm{~m}$ & $\mathrm{~m} / \mathrm{s}$ \\
DT25m & Prolazno vrijeme trčanja na $25 \mathrm{~m}$ & $\mathrm{~s}$ \\
DV25m & Brzina trčanja na $25 \mathrm{~m}$ & $\mathrm{~m} / \mathrm{s}$ \\
DT30m & Prolazno vrijeme trčanja na $30 \mathrm{~m}$ & $\mathrm{~s}$ \\
DV30m & Brzina trčanja na $30 \mathrm{~m}$ & $\mathrm{~m} / \mathrm{s}$ \\
DT35m & Prolazno vrijeme trčanja na $35 \mathrm{~m}$ & $\mathrm{~s}$ \\
DV35m & Brzina trčanja na $35 \mathrm{~m}$ & $\mathrm{~m} / \mathrm{s}$ \\
DT40m & Prolazno vrijeme trčanja na $40 \mathrm{~m}$ & $\mathrm{~s}$ \\
DV40m & Brzina trčanja na $40 \mathrm{~m}$ & $\mathrm{~m} / \mathrm{s}$ \\
DT50m & Rezultat trčanja na $50 \mathrm{~m}$ & $\mathrm{~s}$ \\
DV50m & Brzina trčanja na $50 \mathrm{~m}$ & $\mathrm{~m} / \mathrm{s}$ \\
\hline gnda: DT - prolazno vrijeme; DV - brzina pri svakom prolaznom vremenu
\end{tabular}

Primjenom matematičko-statističkog programa SPSS izračunati su koeficijenti korelacije (prema Pearsonu) između varijabli iz prostora morfoloških obilježja i dinamičkih parametara trčanja.

\section{Rezultati}

Na grafikonu 1, na liniji kojom je predstavljena brzina trčanja tokom intervala prolaznog vremena, kao konačni moment trajanja faze akceleracije je definisana dostignuta brzina na 15 . metru dionice. Uočljivo je da se prosječna vrijednost brzine trčanja održavala na ujednačenom nivou od 20. do 40. metra, a njen maksimalni nivo je dosegnut na 30 metru dionice trčanja na 50 metara. Evidentna je neznatna tendencija opadanja brzine u intervalu od 30. do 40. metra. U skladu s tim se može definisati trajanje stabilne faze trčanja $u$ intervalu od 15 . do 40 . metra, obzirom da se i njen najniži nivo također podudara sa nivoom brzine koji je dostignut tokom faze akceleracije. Faza deceleracije je definisana uočljivim padom brzine trčanja u posljednjih 10 metara dionice.

Faza akceleracije: $0-15 \mathrm{~m}(\mathrm{DV} 15=5,7 \mathrm{~m} / \mathrm{s}$ )

Stabilna faza trčanja: $15-30 \mathrm{~m}(\mathrm{DV}-\mathrm{sf}=5,8 \mathrm{~m} / \mathrm{s})$

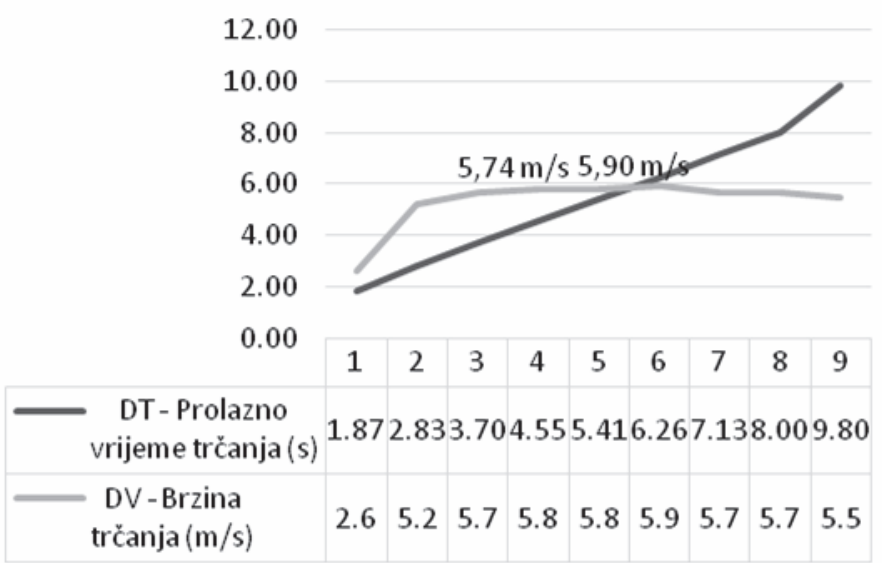

Grafikon 1. Dinamički parametri trčanja na $50 \mathrm{~m}$ i nivo dostignute brzine tokom faze akceleracije i stabilne faze trčanja na distanci 
Varijable iz prostora dinamičkih parametara trčanja DT su ostvarile na nivou statističke značajnosti $(\mathrm{p}<0.05)$ korelacijsku povezanost srednjeg intenziteta sa varijablama za procjenu transverzalne dimenzionalnosti (ATDZK), varijablama za procjenu volumene i mase tijela (AVNAD, AVNAT, AVMT), te svim varijablama za procjenu potkožnog masnog tkiva. Također je dobivena statistički značajna povezanost $(\mathrm{p}<0.01)$ srednjeg intenziteta između varijable indeks tjelesne mase (ABMI) i svih varijabli kojima je procijenjena DT (tabela 2).

Tabela 2. Povezanost morfoloških obilježja i prolaznog vremena trčanja

\begin{tabular}{|c|c|c|c|c|c|c|c|c|c|}
\hline Varijabla & DT5 & DT10 & DT15 & DT20 & DT25 & DT30 & DT35 & DT40 & DT50 \\
\hline \multirow[t]{2}{*}{ ALVT } & ,019 & ,012 &,- 018 &,- 049 &,- 056 &,- 080 &,- 100 &,- 120 &,- 125 \\
\hline &, 873 & 918 & ,877 & ,679 &, 630 & ,492 & ,391 & ,305 & ,286 \\
\hline \multirow[t]{2}{*}{ ALDN } &, 037 &, 022 &, 011 &,- 016 &,- 013 &,- 026 &,- 048 &,- 060 &,- 059 \\
\hline & ,751 &, 851 & ,925 & ,892 & ,909 &, 822 & ,681 & ,608 & ,618 \\
\hline \multirow[t]{2}{*}{ ALDST } & ,008 &, 016 &, 010 & ,008 & 006 &,- 020 &,- 032 &,- 044 &,- 049 \\
\hline & ,944 &, 895 & ,931 & 947 & ,956 &, 868 &, 784 &, 706 &, 676 \\
\hline \multirow[t]{2}{*}{ ATŠR } &,- 089 &,- 091 &,- 082 &,- 097 &,- 066 &,- 061 &,- 086 &,- 082 &,- 079 \\
\hline &, 450 &, 439 &, 485 &, 410 &, 576 & ,602 &, 464 & ,486 & ,499 \\
\hline \multirow[t]{2}{*}{ ATŠZ } &, 012 &, 003 & ,009 & ,002 & 026 & 027 &, 004 & 014 & 018 \\
\hline & ,922 & ,978 & ,938 & ,986 & ,827 &, 817 & ,976 & 904 &, 875 \\
\hline \multirow[t]{2}{*}{ ATDSZ } &,- 017 & ,016 &, 014 & 013 & 019 & ,001 &,- 008 &,- 022 &,- 025 \\
\hline &, 883 & ,893 & ,903 & 909 & 875 & ,995 & ,948 &, 848 &, 832 \\
\hline \multirow[t]{2}{*}{ ATDZK } & ,359 & ,341 &, 310 & 287 & 268 & ,217 &, 210 & 194 & 179 \\
\hline &, 002 &, 003 &, 007 & 013 & 020 & 061 &, 071 & 095 &, 124 \\
\hline \multirow[t]{2}{*}{ AVNAD } & 307 & ,318 &, 316 & 291 & 290 & ,261 &, 240 &, 228 &, 225 \\
\hline & ,007 &, 005 &, 006 & 011 & 012 & 024 &, 038 & 049 &, 052 \\
\hline \multirow[t]{2}{*}{ AVNAT } & ,265 & ,272 & ,249 & 232 & 223 & 198 &, 178 &, 163 &, 154 \\
\hline & 022 &, 018 &, 031 & 045 & 054 & 089 &, 127 &, 163 &, 187 \\
\hline \multirow[t]{2}{*}{ AVPOT } & ,206 & ,212 & ,201 & 182 & 179 &, 156 &, 139 & 126 &, 123 \\
\hline &, 076 & ,068 &, 084 &, 119 & 124 &, 182 & ,236 & 282 & ,293 \\
\hline \multirow[t]{2}{*}{ AVMT } & ,269 & ,282 & ,271 & 251 & 250 &, 224 & ,203 & 189 & 190 \\
\hline & ,019 &, 014 & ,019 & 030 & 030 &, 053 &, 081 &, 105 & 103 \\
\hline \multirow[t]{2}{*}{ ABMI } & ,355 & ,373 & ,374 & 363 & 367 &, 346 & ,329 &, 321 & ,323 \\
\hline &, 002 & ,001 &, 001 & 001 & ,001 &, 002 &, 004 &, 005 & ,005 \\
\hline \multirow[t]{2}{*}{ ANL } &, 424 & ,477 &, 490 & ,480 & ,483 & ,454 &, 445 &, 441 & ,446 \\
\hline &, 000 &, 000 &, 000 &, 000 & ,000 &, 000 &, 000 &, 000 & 000 \\
\hline \multirow[t]{2}{*}{ ANS } &, 345 & ,392 & ,399 & ,389 & ,384 & 361 &, 345 & 336 & ,337 \\
\hline &, 002 &, 001 &, 000 & 001 & 001 & ,001 &, 002 & 003 &, 003 \\
\hline \multirow[t]{2}{*}{ ANTRI } & ,362 &, 418 &, 431 & ,419 &, 431 & ,411 & ,397 & ,398 & ,403 \\
\hline &, 001 &, 000 &, 000 &, 000 & 000 &, 000 &, 000 &, 000 &, 000 \\
\hline \multirow[t]{2}{*}{ ANBIC } &, 383 &, 420 &, 422 & 402 & 404 & 379 &, 364 &, 357 &, 356 \\
\hline &, 001 &, 000 &, 000 &, 000 &, 000 & 001 &, 001 &, 002 &, 002 \\
\hline \multirow[t]{2}{*}{ ANPOT } & ,348 & ,406 & ,419 & ,398 & ,403 & ,386 & ,375 & ,364 & ,364 \\
\hline &, 002 &, 000 &, 000 &, 000 &, 000 & 001 &, 001 &, 001 &, 001 \\
\hline
\end{tabular}

Varijable iz prostora dinamičkih parametara trčanja DV su ostvarile korelacijsku povezanost na nivou statističke značajnosti $(p<0.05)$ dominantno sa varijablama za procjenu potkožnog masnog tkiva (tabela 3 ).

\section{Diskusija}

Na osnovu rezultata dinamičkih parametara trčanja može se zaključiti da analizirani uzorak dječaka uzrasta 10-12 godina karakterizira sljedeći model strukture trčanja na 50 metara: faza akceleracije trčanja u trajanju od starta do 15 . metra dionice; stabilna faza održavanja trčanja u trajanju od 15. do 40. metra, što ukazuje da prostorno trajanje ostvarenog nivoa maksimalne brzine iznosi 25 metara; faza deceleracije brzine u trajanju od 40. do 50. metra dionice.

Uporedba dobivenog modela strukture trčanja na 50 metara na uzorku dječaka uzrasta 10-12 godina sa prostornim trajanjem modela strukture trčanja u slučaju vrhunskih sprintera (Č́oh, Bračić \& Smajlović 2010, Mero i sar. 1992; Ae, Ito \& Suzuki, 1992, Chapman \& Caldwell, 1983) na 100 metara (faza akceleracije $0-30 \mathrm{~m}$, faza održavanja maksimalne brzine $30-80 \mathrm{~m}$ i faza deceleracije 80-100m), ukazuje da dječaci u ovom uzrastu ostvaruju svoj bio-motorički potencijal brzine trčanja prema sličnoj strukturi kao vrhunski sprinteri, ali pri upola kraćem prostornom trajanju definisanih faza akceleracije, stabilne faze i deceleracije brzine trčanja.

Povezanost varijabli za procjenu transverzalne dimenzionalnosti, volumena i mase tijela i potkožnog masnog tkiva sa varijablama prolaznog vremena (DT) ukazuju da ove dimenzije mogu biti remeteći faktor pri dinamici trčanja na $50 \mathrm{~m}$ u slučaju analiziranog uzorka dječaka. Na ovaj zaključak također ukazuju i ustanovljene korelacijske povezanosti srednjeg intenziteta između varijable indeks tjelesne mase i svih varijabli kojima je sagledano prolazno vrijeme trčanja (DT). Važno je istaknuti da se vrhunski sprinteri odlikuju laganom konstitucijom i optimalnom mišićnom masom, ali to opet nisu jedini relevantni faktori razvoja brzine, nego i učinkovitost biohemijskih energetskih procesa (Čoh i sar., 2001).

Obzirom da su u slučaju varijabli kojima je procijenjena brzina trčanja (DV) ustanovljene korelacijske povezanosti na visokom nivou statističke značajnosti, te također i sa svim varijabla za procjenu potkožnog masnog tkiva, može se konstatovati da potkožno masno tkivo ima negativnu refleksiju na 
ispoljavanje bio-motoričkog potencijala brzine u slučaju dječaka uzrasta 10-12 godina i njihovu rezultatsku uspješnost u trčanju na $50 \mathrm{~m}$. Dobivena korelacijska povezanost srednjeg intenziteta između varijable indeks tjelesne mase sa varijablama prolaznog vremena u intervalu od 5. do 15 . metra može ukazivati da potkožno masno tkivo prvenstveno predstavlja remeteći faktor tokom faze akceleracije. Korelacijska povezanost varijable obim natkoljenice sa varijablama iz prostora dinamičkih parametara trčanja (DT) može ukazivati na bio-motorički potencijal jačine mišića koji su dominantno odgovorni za pokrete pri ispoljavanju brzine trčanja. Ipak, sva navedena opažanja mogu prvenstveno navoditi na zaključak da je znatan broj ispitivanih dječaka ima povećane vrijednosti masnog tkiva, te da se ove adipozne naslage prvenstveno odnose na pojas stomaka i leđa.

Tabela 3. Povezanost morfoloških obilježja i brzine trčanja

\begin{tabular}{|c|c|c|c|c|c|c|c|c|c|c|c|c|c|c|c|}
\hline & & & ASS1 & ŠR & TŠZ & $\mathbf{D S}$ & DV & VNA & $\sqrt{ } N A$ & VIP & AVMT & ABMI ANL AN & ANTR & I ANBI & ANPC \\
\hline \multirow[t]{2}{*}{ DV5 } &,- 040 &,- 058 &,- 026 & ,076 &,- 030 & 000 &,- 366 &,- 312 &,- 276 &,- 225 &,- 283 &,$- 359-, 415-, 345$ &,- 361 &,- 379 &,- 354 \\
\hline & ,732 & ,620 &, 823 &, 518 & ,802 & ,999 &, 001 & ,006 &, 017 &, 052 &, 014 & 002, 000, &, 001 &, 001 & ,002 \\
\hline \multirow[t]{2}{*}{ DV10 } & ,009 &, 031 &,- 037 & ,060 &, 022 &,- 100 &,- 157 &,- 220 &,- 184 &,- 146 &,- 206 &,$- 276-, 428-, 367$ &,- 409 &,- 358 &,- 410 \\
\hline & ,936 &, 791 &, 751 & ,609 &, 850 & ,392 & , 178 &, 058 &, 113 &, 210 &, 076 & 001, 000, 017, &, 000 &, 002 &, 000 \\
\hline \multirow[t]{2}{*}{ DV15 } &, 120 & ,039 &, 040 & ,034 &,- 023 &, 016 &,- 112 &,- 185 &,- 085 &,- 083 &,- 136 &,$- 243-, 363-, 284$ &,- 312 &,- 278 &,- 300 \\
\hline & ,304 &, 743 &, 733 & ,774 &, 844 &, 888 &, 339 &, 112 & ,468 & ,478 &, 244 & 014, 001, 036, &, 006 &, 016 &, 009 \\
\hline \multirow[t]{2}{*}{ DV20 } & ,168 &, 116 & ,022 & ,129 &, 031 &, 004 &,- 097 &,- 108 &,- 096 &,- 052 &,- 095 & -,219-,311 -,244 &,- 261 &,- 216 &,- 213 \\
\hline &, 151 &, 323 &, 854 &, 270 &, 790 & ,973 & ,408 &, 357 & ,414 & ,658 &, 420 & 035, 007, 058, &, 024 & ,062 &, 067 \\
\hline \multirow[t]{2}{*}{ DV25 } & 084 &, 024 &, 004 &,- 006 &,- 048 &,- 004 &,- 157 &,- 142 &,- 073 &,- 070 &,- 125 &,$- 219-, 355-, 257$ &,- 331 &,- 297 &,- 306 \\
\hline & ,476 &, 840 &, 976 & ,960 & ,686 &, 975 &, 178 &, 223 &, 536 &, 552 &, 287 & 026, 002, 059, &, 004 &, 010 &, 008 \\
\hline \multirow[t]{2}{*}{ DV30 } & ,177 &, 083 &, 140 & ,024 &,- 027 &, 084 &, 066 &,- 073 &,- 041 &,- 025 &,- 059 &,$- 176-, 221-, 180$ &,- 229 &,- 184 &,- 233 \\
\hline &, 129 &, 480 & ,229 & ,836 &, 815 & ,472 &, 573 &, 533 &, 729 &, 831 & ,614 & 122, 057, 132, &, 048 &, 115 &, 044 \\
\hline \multirow[t]{2}{*}{ DV35 } & ,192 & , 143 & ,098 & ,195 &, 115 &, 061 &,- 122 &,- 089 &,- 044 &,- 028 &,- 060 &,$- 191-, 326-, 212$ &,- 260 &,- 229 &,- 260 \\
\hline & ,099 & ,220 & ,404 & ,094 &, 328 & ,605 & ,298 & ,449 &, 707 & ,808 & ,607 & 068, 004, 101, &, 024 &, 048 & ,024 \\
\hline \multirow[t]{2}{*}{ DV40 } & ,237 & ,133 &, 121 &, 051 &,- 068 &, 117 &,- 057 &,- 106 &,- 035 &,- 028 &,- 065 &,$- 220-, 340-, 225$ &,- 339 &,- 257 &,- 244 \\
\hline &, 040 &, 256 &, 302 & ,665 &, 563 &, 315 &, 627 &, 367 &, 764 &, 813 &, 581 & 052, 003, &, 003 &, 026 &, 035 \\
\hline \multirow[t]{2}{*}{ DV50 } &, 125 &, 052 &, 061 &, 075 &,- 026 &, 027 &,- 131 &,- 185 &,- 103 &,- 094 &,- 168 & $\begin{array}{l}-, 289-, 405-291 \\
-, 2\end{array}$ &,- 371 &,- 295 &,- 316 \\
\hline & ,287 & ,656 & 601 &, 523 &, 825 &, 815 &, 264 &, 112 &, 381 & ,421 & , 149 & 012, 000, &, 001 &, 010 &, 006 \\
\hline
\end{tabular}

Brzina trčanja je urođena bio-motorička sposobnost, te se smatra da ima ograničene mogućnosti razvoja. U skladu s tim važno je istaknuti da bio-motorički potencijal brzine trčanja zavisi od različitih faktora koji su povezani sa morfološkim i fiziološkim karakteristikama, energetskim mehanizmima, starosnom dobi, genetskim naslijeđem, motoričkim sposobnostima, intermuskularnom i intramuskularnom koordinacijom, te optimalnom biomehaničkom tehnikom kretanja (Čoh i sar. 2010).
Porast maksimalne brzine trčanja je također posljedica promjena morfoloških odlika adolescenata. Ove morfološke promjene su posljedica upliva genetskih, ali i drugih vanjskih faktora (Bračič i sar. 2009). Ipak, važno je ukazati da se na bio-motorički potencijala brzine može utjecati ciljano programiranim atletskim treningom trčanja, koji treba biti prvenstevno usmjeren na razvoj koordinativnih kvaliteta dječaka u ovom uzrastu.

\section{R E F E R E N C E S}

Ae, M., Itto, A. \& M. Suzuki (1992). The men's 100 m. New Studies in Athletics, 7 (1), 47-52.

Bračič, M., K. Tomažin, M. Čoh (2009). Dejavniki razvoja maksimalne hitrosti pri mladih atletinjah starih od 7 do 14 let. Ljubljana: Fakulteta za šport, Inštitut za kineziologijo.

Buenen, G., \& Malina, R. (1988). Growth and Physical Perfomance Relative to the Timing the Adolescent Spurt. Exercise \& Sport Sciences Reviews (16), 503-540.

Chapman A.E., \& G.E. Caldwell (1983). Kinematic limitations of maximal sprinting speed. Journal of Biomechanics, 16 (1), 79-83.

Čoh, M., S. Mihajlovič, i U. Praprotnik (2001). Morfološke in kinematične značilnosti vrhunskih šprinterjev. U M. Čoh (ur.) Biomehanika atletike. Ljubljana: Fakulteta za šport.

Čoh, M., M. Bračić i N. Smajlović (2010). Methodical aspects of maximum speed development. Sport Science, 3(2), 1114.

Malina, R. M. (1984). Human growth, maturation and regular physical activity. V: Boileau R. A. (ed.) Advances in pediatric sport sciences (vol. 1). Biological issues. Champaign, Illinois: Human Kinetics, 59-83.

Mero, A., P.V. Komi, \& R.J. Gregor (1992). Biomechanics of sprint running: A rewiew. Sports Medicine, 13, 376-392.

Prapotnik, U. \& M. Čoh (2001). Razlike v šprinterskem teku mladih atletov, starih 10 do 15 let. Biomehanika atletike. Fakulteta za šport Univerze v Ljubljani.

Smajlović, N. (2010). Atletika. Fakultet sporta i tjelesnog odgoja Univerziteta u Sarajevu.

\section{S. Likić}

University of Sarajevo, Faculty for Sport and Physical Education, Patriotske lige 41, 71000 Sarajevo, Bosnia and Herzegovina e-mail:slavenkolikic@gmail.com 